SPINE An International Journal for the study of the spine Publish Ahead of Print

DOI: 10.1097/BRS.0000000000002390

\title{
Performance on Balance Evaluation Systems Test (BESTest) impacts health-related quality of life in Adult Spinal Deformity Patients
}

Lieven Moke, MD ${ }^{1,2}$, Pieter Severijns, M.Sc. ${ }^{1,3}$, Sebastiaan Schelfaut, MD ${ }^{1,2}$, Kristel Van de loock, M.Sc. ${ }^{1}$, Lore Hermans, M.Sc. ${ }^{1}$, Guy Molenaers, PhD $^{1,2}$, Ilse Jonkers, PhD ${ }^{3}$, Lennart Scheys, $\mathrm{PhD}^{1,2}$

Affiliations:1 Institute for Orthopaedic Research and Training (IORT), Department of Development and Regeneration, Faculty of Medicine, KU Leuven, 2 Division of Orthopaedics, University Hospitals Leuven, Belgium 3 Department of Rehabilitation Sciences, KU Leuven

Address correspondence and reprint requests to Lieven Moke, MD, Division of Orthopaedics, University Hospitals Leuven, Weligerveld 1, B3212 Pellenberg, Belgium; Fax number: 003216/33.88.24; Telephone number: 003216/33.88.27; E-mail address: Lieven.Moke@uzleuven.be

The manuscript submitted does not contain information about medical device(s)/drug(s).

The Research Foundation-Flanders, the KU Leuven Medtronic Educational Chair for spinal deformity research, and Klinisch Onderzoeksfonds (KOF) UZ Leuven funds were received in support of this work.

Relevant financial activities outside the submitted work: consultancy, grants.

Copyright @ 2017 Wolters Kluwer Health, Inc. Unauthorized reproduction of this article is prohibited. 
Study Design: Prospective single-center study

Objective: This study investigates how dynamic balance performance complements 2D static radiographic measurements and demographics in terms of understanding health-related quality of life in Adult Spinal Deformity (ASD) patients.

Summary of Background Data: Recent insights suggest that demographic variables have a stronger impact on health-related quality of life than 2D radiographic spinopelvic parameters in ASD patients

Methods:9 Healthy volunteers and 36ASD patients following inclusioncriteria were recruited. Demographics, Scoliosis Research Society Score-22r (SRS-22r),

OswestryDisability Index (ODI), Core Outcome Measures Index(COMI),2D radiographic spinopelvic measurements and performance on Balance Evaluation Systems Test (BESTest) and Trunk Control Measurement Scale (TCMS) were determined for each subject. Nonparametric tests, Spearman correlations, univariate and stepwise-like linear multivariate regression analysis were performed.

Results:BESTest and TCMS had significant lower values in the ASD group versus the control group $(\mathrm{p}=0,000)$. In the ASD group, Cumulative Illness Rating Scale (CIRS) correlated fair to ODI, COMI $(0,441 \geq r \geq 0,383, p<0,021)$ and to SRS-22-r $(r=-0,335, p=0,046)$, Mini Mental State Examination correlated fair to COMI ( $\mathrm{r}=-0,352, \mathrm{p}=0,035)$, 'Pelvic Incidence minus Lumbar Lordosis’ correlated fair to ODI ( $r=0,361, \mathrm{p}=0,031)$, BESTest correlated moderate to ODI and COMI ( $r \leq-0,505 ; \mathrm{p} \leq 0,002)$, TCMS correlated fair to ODI ( $\mathrm{r}=-$ 0,356; $\mathrm{p}=0,033$ ). CIRS and BESTest were significant predictive variables for COMI based on univariate analysis in ASD patients. Multivariate regression analysis including demographics, 2D static radiographic parameters and dynamic balance scales identified BESTest as single independentvariable $(p=0,000)$ to predict COMI (adjusted $\left.\mathrm{R}^{2}=0,285\right)$ in ASD patients.

Conclusions:BESTest has a higher potential than demographic and 2D radiographic spinopelvic parameters to predict quality of lifein ASD patients.Further research is necessary to identify the impact of ASD on quality of life.

KeyWords: Adult SpinalDeformity, Balance Evaluation Systems Test, BESTest, Quality of life, Multivariate Regression Analysis

Level of Evidence: 3 


\section{Introduction.}

Patient status in Adult Spinal Deformity (ASD) is currently typically assessed using Health Related Quality of Life measures (HRQOL) in combination witha set of static 2D radiographic measurements.To quantify HRQOL, general functional outcome scores, as the Oswestry Disability Index (ODI) and Core Outcome Measurement Index (COMI)(1-3)have been introduced, as well as spinal deformity-specific scores,such as SRS-22r (4-5). With regards to 2D radiographic measurements, the SRS-Schwab Classification iscurrently one of the most established classification systems for ASD with demonstrated good inter- and intrarater reliability (6-8). It provides a coronal description of the curve (Thoracic only, TL/Lumbar only, Double Curve, no major coronal deformity) in combination withsagittal measurements, including Pelvic Incidence minus Lumbar Lordosis (PI-LL), Sagittal Vertical Axis (SVA) and Pelvic Tilt (PT). Next to the SRS-Schwab Classification, other global radiographic spinopelvic parameters like T1 spinopelvic inclination angle (T1 SPI), T1 Pelvic Angle (TPA),Global Sagittal Axis (GSA) have been introduced to quantify global alignment in ASD subjects(9-15).Supported by arange of studiesdemonstrating correlations $(\mathrm{r}<0,55)$ between HRQOL and several spinopelvic radiographic measurements(8-10,16-22), the latter have evolved into the single most important and reliable surgical targetforachieving improvement inHRQOLin adult spinal deformity surgery (23).However, past literature was based on a mixed ASD-population also including iatrogenic deformity with or without previous spinal instrumentation. Arecent paper of Chapman et al. - explicitly excluding any iatrogenic deformity - states that static radiographic parameters only show no to weak correlations with HRQOL-scores (24). Other recent studiesattempting to clarifythe impact of spinal deformityon quality of life in ASD stated that demographic dataas opposed to spinopelvic parameters have the largestinfluence on HRQOL(25-27). As such, these more recent insights suggest that 2D spinopelvic radiographic parameters are not the sole drivers of quality of life in ASD.

Furthermore, as radiographic spinopelvic parameters quantify postural changes only in an upright, standing posture and not during dynamic activities of daily life (28), no conclusions whatsoever can be drawn with respect to postural control and balance capacities during thesedynamic conditions. Given the primary focus on static radiographic parameters in the literature, only little information is currently available regarding this dynamic impact of ASD. Some earlier studies suggest a multifactorial etiology of impaired balance control (29-33) represented by the line of gravity fallingoutside the base of support, which in turn leads to 
poor stability in upright standing. In parallel, Dubousset introduced the 'cone of economy' principle, which represents the range in which a body is balanced and stable without external support or excessive energy expenditure (34). Other studies looking into compensation mechanisms in patients with spinal deformity reportedthe use of multiple musculoskeletal compensation strategies to compensate for the abnormal spinal alignment and reorient the gravity line position within their base of support (35-41).

Clinical scales for quantifying balance performance, therefore, have clear potential to deepen our understanding of potential dynamic drivers of HRQOL in adults with spinal deformity.Such balance assessment scaleshave been described in the literature for use in a variety of musculoskeletal and neurological conditions associated with balance impairment (42-50) such as the Berg Balance Scale, Physical Performance Test and modified Physical Performance Test. In e.g. Parkinson disease and stroke, these balance assessment scales evolved into a key clinical assessment tool. However,as these specific scales are primarily targeting lower functioning elderly,the associated ceiling effect makes them lesssuitableto asses balance in community dwelling ASD subjects (51-54). Similarly, the Fullerton Advanced Balance Scale and Trunk Impairment Scale (TIS) do not seemimmediately applicable in ASD, because, respectively, the tested itemsare too demanding in an ASD population which might include subjects with osteoporosis $(55,56)$ or the testdoes not prevent lower limb compensations during trunk control assessment(57-60).On the other hand, certain scales seem more straightforwardly applicable in ASD populations. The Trunk Control Measurement Scale (TCMS) evaluatesthree-planar movements in, but also outside of, the base of support while the patient is sitting without feet support, thuslimiting lower limb compensations(61). However, normative adult TCMS-scoreshave until now not yet been reported in the literature. Finally, the Balance Evaluation Systems Test (BESTest) is a relatively new balance assessment tool used in neurological as well as musculoskeletal disorders (62-63). A specific feature of interest of the BESTestis its use of subscales,allowing to scoreindividual components of the postural system: biomechanical constraints, stability limits/verticality, anticipatory postural adjustments, postural responses, sensory orientation and stability in gait. Furthermore, normative adult BESTest scoresare available in the literature(64-66). Based on the above appraisal, the TCMSand BESTest seem to be the most promising tests to assess balance in ASD $(67,68)$.

Therefore, the objective of this paper is to investigate how dynamic balance performance as quantified by the BESTest and TCMS complements the currently used analysis of 2D static 
spinopelvic alignment and demographicsin terms of understanding ASD's impact on healthrelated quality of life scores. We hereby hypothesize that the combined use of 2D spinopelvic radiographic measurements and balance assessment scales hasa higher predictive value towardsHRQOL than each analysis individually.

\section{Material and Methods.}

Following ethical approval and informed consent by our institution's ethical committee (S58082), a convenience sample of 36 ASD subjects in a pre-and nonsurgical settingwas recruited and clinically screened for compliancewith following inclusion criteria: adults suffering from a spinal deformity with or without sagittal malalignment, agedbetween 18 and 79 years, Mini mental state examination (MMSE) $\geq 25$, able to walk at least 50 meters distance independently, no current history of diagnosed musculoskeletal disorders of the lower extremities affecting motor performance such as severe hip arthrosis with or without flexion contracture, severe knee arthrosis, severe ankle arthrosis, severe leg length discrepancy (> 3 $\mathrm{cm}$ ), no history of neurological disease affecting balance such as stroke, Parkinson disease or vestibular lesion, no history of spinal fusion surgery. Additionally, 9 asymptomatic adults without major coronal deformity and with non-pathological sagittal alignment were recruited.

Demographic variables, 2D radiographic parameters (coronal SRS Schwab classification and spinopelvic parameters)and performance on clinical balance assessment scales (BESTest and TCMS) were determined for each study subject (Table 1). Spinopelvic alignment was quantified in each subject through full body bi-planar X-ray images(EOS, EOS imaging, Paris, France) acquired in the SRS free standing position(Figure 1)using IMPAX Data Center viewer (Agfa Healthcare, Mortsel, Belgium) by an adult spinal deformity surgeon experienced in the definition and use of spinopelvic parameters (LM). Health-related quality of life was quantified ineach subject throughvalidated SRS-22r, ODI and COMI questionnaires. Balance performance was quantified in each subject through bothBESTest and TCMS by an experienced physiotherapist (PS), specifically following the guidelines of Horak et al. for the BESTest and Heyrman et al. for TCMS (61,62,69)(Figure 2). The average length of BESTest and TCMS in our cohort of ASD patients, taking respectively 25and 15 minutes to perform, is still within acceptable limits in terms of clinical utility and feasibility of these tests. 
First, all variables were statistically compared between the ASD and control group using nonparametric Mann-Whitney U test,exceptfor gender and coronal SRS-Schwab classification (Chi-square test).Significance level was set at $\mathrm{p}<0,05$, including for all further analyses. Next, correlations between HRQOL-scores and demographic variables, 2D radiographic parameters as well as clinical balance assessment scales were calculated within the ASD group(Spearman, $r<0,25=$ little to no correlation, $0,25<r<0.50=$ fair, $0,50<r<0,75=$ moderate, and $0,75<\mathrm{r}<1,00=$ high correlation) (51).Finally, both univariate and multivariate linear regression analyses wereconducted to identify significant predictive variables for HRQOL in ASD patients. Justified by the mutual correlations within the collected HRQOL-scores $(r>0,80, p<0,001)$, we selecteda single HRQOL-score as dependent variable to simplify the furtherlinear regression analyses. COMI was selected due toits brevity, favorable psychometric properties and responsiveness to change following treatment being comparable to the disease-specific SRS-22r. Prior to regression analysis, the applicable assumptions were checked (continuous dependent variable, 2 or more independent variables, independence of observations, linear relationship, homoscedasticity, multicollinearity, no significant outliers, high leverage points or highly influential points, normal distribution of residuals). If required for univariate regression analysis,transformation of independent variables was performed.For every original independent and transformed (squared, logistic, square root) independent variable, a univariate linear regression analysis was performed.Next, four stepwise multivariate models were developed with varying input sets of independent variables:

- model 1: only demographic variables(age ${ }^{2}$, gender, $\mathrm{BMI}^{2}, \mathrm{MMSE}^{2}$ and CIRS)

- model 2: adding spinopelvic parameters $\left(\mathrm{PI}^{2}, \log (\mathrm{SS}), \mathrm{PT}^{2}, \mathrm{PI}-\mathrm{LL}, \mathrm{SVA}, \mathrm{T} 1 \mathrm{SPI}^{2}\right.$, sqrt(TPA), GSA) and SRS-Schwab coronal classification (T,D,L,N) as predictors to model 1

- $\quad$ model 3: adding total score on BESTest(in \%) and TCMS ${ }^{2}$ as predictors to model 1

- model 4: adding total score BESTest (in \%) and $\mathrm{TCMS}^{2}$ as well as all spinopelvic parameters $\left(\mathrm{PI}^{2}, \log (\mathrm{SS}), \mathrm{PT}^{2}\right.$, PI-LL, SVA, T1 $\mathrm{SPI}^{2}$, sqrt(TPA), GSA) and SRSSchwab coronal classification (T,D,L,N) as predictors to model 1

All analyses were carried out using IBM SPSS version 24 (IBM Corporation, New York, USA) and reviewed by a bio-statistician. 


\section{Results.}

All collected demographic variables, HRQOL-scores,SRS-Schwab coronal classification, spinopelvic radiographic parameters, BESTest and TCMS scoresare listed in Table 1. Spinal alignment in terms of coronal SRS-Schwab classification, PI-LL, SVA and GSA is significantly different between both groups illustrating the presence of spinal malalignment in the ASD group. Performance on TCMS and BESTest is significantly more impaired in the ASD group than in the control group. In terms of demographic correlations with HRQOLscores, CIRS was found to correlate fairlywith all HRQOLscores $(0,441 \geq r \geq 0,335$; $<<0,046)$ whereasMMSEonly correlatedfairlywith COMI ( $r=-0,334$; $\mathrm{p}=0$,047).In terms of radiographic correlations with HRQOL, PI-LLwas the only parameter which correlated fairlywith ODI $(\mathrm{r}=0,361 ; \mathrm{p}=0,031)$. All other demographic and 2D radiographic variables were not found to correlate with HRQOL-scores $(r<0,25)$.Finally, with regards to the correlations between balance assessment scales and HRQOL, BESTestwas found to show moderate correlations with both ODI and COMI $(-0,505 \geq r \geq-0,519 ; p \leq 0,002)$. TCMSon the other hand, only correlated fairlywith ODI(r=-0,356; $\mathrm{p}=0,033)$.

Subsequent univariate linear regression analysis in ASD only identified CIRS and BESTest as significant predictive variables. Although MMSE, PI-LL and TCMSindividually demonstrated significant correlations with HRQOL-scores, these variables were not identified as significant predictive variables (Table 2).

Thenastepwiselinear multivariate regression analysis using the selected independent variables based on the aforementioned univariate analysis was performed.The first and second multivariate model identified comorbidity (CIRS) as independent predictive variable for COMI $(\mathrm{p}=0,019)$ (adjusted $\left.\mathrm{R}^{2}=0,126\right)$. Forthe third and fourth model BESTestwas twice retained as the only independent predictive variable $(\mathrm{p}<0,001)$ for predicting COMI(adjusted $\mathrm{R}^{2}=0,285$ ) (Table 2 ), rejecting our mainhypothesis.

\section{Discussion.}

With regard to our study objective, we hypothesized that the combined use of 2D spinopelvic radiographic measurements and balance assessment scales would better explain variations in HRQOL in ASD than their individual explanatory abilities.Therefore, we explored the 
potential valueto combinedynamic balance assessment scales with 2D radiographic and demographic variables in a stepwise multivariate regression analysis(model 4) to predict health-related quality of life in our ASD population. Balance performance on BESTest was retained as the only independent variable $(\mathrm{p}<0,001)$ for predicting COMI in model 4 and explains nearly $30 \%$ of the variance of COMI in our ASD patients.However, model 3, which includes balance assessment scales combined with demographic variables, seems to provide equally significant predictive value for HRQOL in comparison to model 4. Based on these conclusions and very much to our surprise, we have to reject our hypothesisthat combined use of 2D spinopelvic radiographic measurements and balance assessment scales has a higher predictive value towards HRQOL than each analysis individually, since model 4 does not demonstrate an increased predictive power for COMI compared to single use of dynamic balance assessment scales on a demographic background (model 3).As we observed a high correlation between all HRQOL-scores, the results of our multivariate regression analysis can be extrapolated to ODI and SRS-22-r. Furthermore, this multivariate regression analysis shows that TCMS seems less appropriate to use as predictor for COMI in ASD compared with BESTest.

To compare our multivariate regression analyses including dynamic balance assessment scales (model 3 and 4) to the standard model in literature (25-27),model 2 also analyzed the predictive power for HRQOL in ASD using 2D spinopelvic radiographic parameters combined with demographic variables. The multivariate regression model 2 identifies comorbidity (CIRS) as unique significant predictive variable with nearly $13 \%$ explained variance for COMI which is less than half the number of explained variance for COMI in model 3 and 4 (Figure 3). This illustrates that dynamic balance assessment scales have the potential to deepen our understanding in the drivers of HRQOL in ASD.To improve insights, into the influence of a spinal deformity on balance performance this study conducted a comparison between both study groupswhich confirms impaired balance performance in ASD patients(Table 1). Analysis of subscale scores illustrates that ASD subjects score lower on dynamic items in TCMS and all items in BESTest. As demographic variables like age, BMI and cognitive impairment (MMSE) which have been identified in the literature as factors to negatively influences balance performance (70-72) were not significantly different between both study groups, these variables do not explain worse performance in the ASD group. As potential diseases affecting balance performance were excluded from this study, we believe 
that the decreased performance of ASD patients on BESTest is associated with the presence of spinal deformity.

In accordance with past literature $(25,26)$, multivariate regression analysis model 2, which uses 2D spinopelvic radiographic parameters combined with demographic variables, confirms that demographic variables have a stronger impact on health-related quality of life than $2 \mathrm{D}$ radiographic spinopelvic parameters.However, in contrast to previous papers which identify also other demographic variables as predictors for HRQOL in ASD, model 2 identifies comorbidity (CIRS) as unique significant predictive variable. Our older ASD study group ( \pm 10 years older compared to other studies) may explain this difference with past literature.

The explained variance for COMI in model 2, 3 and 4 is however lower than the nearly $40 \%$ explained variance for ODI by other demographic variablesin the study of Boissière et al. (26), which includes a larger group of subjects $(n=755)$ with lower mean value of age and BMI and without including comorbidity and dynamic balance assessment scales. We assume that the difference in explained variance and number of variables between our study and past literature can be attributed to thesmaller ASD study group $(n=36)$. This brings us to the first study limitation, i.e. a from a clinical point of view relatively small sample size. Before start of the study, a power analysis wasperformedin function of the Mann-Whitney U tests between ASD and control group.As advanced Parkinson disease often involves spinal deformity and data in the non-neurologic ASD population is not readily available, we based this analysis onreported data of BESTest in a Parkinson population with $\leq 1$ fall (BESTest-score=76,4\% $(\mathrm{SD}=13,6 \%)$ versus normal population (BESTest-score $=91,4 \%(\mathrm{SD}=3,4 \%)$ in age cohort 60 69 years old using a power $1-\beta=80 \%$ and level of significance $\alpha=0,05(65,73)$. Post hoc power analysis on our study data for the Mann-Whitney U test using BESTest confirmed sufficient power $(1-\beta=0,985)$ and sample size of the current study in function of the associated conclusions. Given the relatively small sample size, we furthermore choose to use the stepwise approach in our regression analysis instead of forward or backward analysis. Furthermore, a minimum of 2 subjects per independent variable for adequate estimation of regression coefficients, standard errors and confidence intervals and 10 subjects per significant independent variable for adequate power of the adjusted $\mathrm{R}^{2}$ value is suggested in literature $(74,75)$. In view of the 2 resulting significant variables, it can be concluded that the 36 samples in our study providedsufficient power for all performed tests.Another limitation of the study is thestatisticaldifferencein co-morbidity (CIRS) between our total ASD group versus our control group which could have influencedthe reported difference in balance 
performance between both groups. Despite these limitations, we believe to have shown that dynamic balance assessment scaleshave a huge potential and surpass demographic and static 2D radiographic parameters in terms of understanding the potential drivers of health-related quality of life in ASD.

\section{Conclusion.}

To our knowledge this is the first study to report the use of clinical postural tests in the ASD population. The BESTesthas a higher potentialto predict HRQOL in the primary ASD population than demographic variables and 2D radiographic spinopelvic measurements.Further research is necessary to identify additional drivers of quality of lifein ASD, toexplore the potential of balance performance scales to enhance risk assessment for Proximal Junctional Kyphosis (76) and to offerimproved insights intowhat extent different types of spinal deformity and their surgical correction can impact balance performance as quantified by BESTest and its subscales. From these insights, noveltreatment algorithmscan be developed, including more targeted rehabilitation programs - as e.g. has been demonstrated in other balance-related pathologies like stroke and Parkinson disease $(69,77)$ - to address impaired balance control in the non-surgical, pre-and postsurgical treatment phase. As such the future clinical introduction of these tests provides a clear opportunity to integrate dynamic function in novel treatment pathwaysin view of the in this study documented key rolein the ASD patient'squality of life.

Acknowledgment: the authors thank Annouschka Laenen and Koen Vanbrabant for their help in the statistical analysis (I-Biostat KU Leuven, Belgium) and Myrthe Boijmans for the medical illustration in Figure 1. 


\section{References.}

1. Mannion AF, Porchet F, Kleinstück FS, Lattig F et al. The quality of spine surgery from the patient's perspective. Part 1: The Core Outcome Measures Index in clinical practice. Eur Spine J. 2009;18(SUPPL. 3).

2. Mannion AF, Vila-Casademunt A, Domingo-Sàbat M et al. The Core Outcome Measures Index (COMI) is a responsive instrument for assessing the outcome of treatment for adult spinal deformity. Eur Spine J. 2016;25(8):2638-48.

3. Tonosu J, Takeshita K, Hara $\mathrm{N}$ et al. The normative score and the cut-off value of the Oswestry Disability Index (ODI). European Spine Journal. 2012. p. 1596-602.

4. Gum JL, Bridwell KH, Lenke LG et al. SRS22R Appearance Domain Correlates Most With Patient Satisfaction After Adult Deformity Surgery to the Sacrum at 5-year Follow-up. Spine (Phila Pa 1976). 2015;40(16):1297-302.

5. Crawford 3rd CH, Glassman SD, Bridwell KH et al. The minimum clinically important difference in SRS-22R total score, appearance, activity and pain domains after surgical treatment of adult spinal deformity. Spine (Phila Pa 1976). 2015;40(6):377-81.

6. Schwab F, Ungar B, Blondel B et al. SRS-Schwab Adult Spinal Deformity Classification: A Validation Study. Spine (Phila Pa 1976). 2012;37(12):1077-82.

7. Terran J, Schwab F, Shaffrey CI et al. The SRS-Schwab adult spinal deformity classification: assessment and clinical correlations based on a prospective operative and nonoperative cohort. Neurosurgery 2013 Oct;73(4):559-68.

8. Smith JS, Klineberg E, Schwab Fet al. Change in Classification Grade by the SRSSchwab Adult Spinal Deformity Classification Predicts Impact on Health-Related Quality of Life Measures: Prospective Analysis of Operative and Non-operative Treatment. Spine (Phila Pa 1976) 2013;38(19):1663-71.

9. Glassman SD, Bridwell K, Dimar JR et al. The impact of positive sagittal balance in adult spinal deformity. Spine (Phila Pa 1976) 2005;30(18):2024-9. 
10. Lafage V, Schwab F, Patel A et al. Pelvic tilt and truncal inclination: two key radiographic parameters in the setting of adults with spinal deformity. Spine (Phila Pa 1976) 2009;34(17):pp E599-E606.

11. Protopsaltis T, Schwab F, Bronsard Net al. The T1 pelvic angle, a novel radiographic measure of global sagittal deformity, accounts for both spinal inclination and pelvic tilt and correlates with health-related quality of life. J Bone Joint Surg Am. The American Orthopedic Association; 2014;96(19):1631-40.

12. Protopsaltis TS, Schwab FJ, Smith JS et al. The T1 pelvic angle (TPA), a novel radiographic parameter of sagittal deformity, correlates strongly with clinical measures of disability. Spine J 2013;13(9):61S.

13. Lafage V, Liabaud B, Lafage R et al. Unlocking TPA's clinical and sagittal significance by analyzing its relation to pelvic tilt. Spine Journal. 2015; Volume 15(10). p. S162-S162.

14. Le Huec JC, Saddiki R, Franke J et al. Radiographic Analysis of the Sagittal Alignment and Balance of the Spine in Asymptomatic Subjects. Spine (Phila Pa 1976); 2014;24(2):E1469--76.

15. Diebo BG, Oren JH, Challier V, Lafage R, Ferrero E, Liu S, et al. Global sagittal axis: a step toward full-body assessment of sagittal plane deformity in the human body. $\mathrm{J}$ Neurosurg Spine. 2016; 25(4):494-9.

16. Bronsard N, Protopsaltis T, Moal B et al. T1 Pelvic Angle (TPA): A new global sagittal imbalance radiographic parameter including pelvic tilt and trunk inclination and its correlation with quality of life scores. Eur Spine J 2013;22(5):1218-9.

17. Ha K-Y, Jang W-H, Kim Y-H et al. Clinical Relevance of the SRS-Schwab Classification for Degenerative Lumbar Scoliosis. Spine (Phila Pa 1976) 2016 Mar;41(5): E282-8.

18. Fischer CR, Terran J, Lonner B et al. Factors predicting cost-effectiveness of adult spinal deformity surgery at 2 years. Spine Deform.; 2014;2(5):415-22.

19. Diebo BG, Henry J, Lafage V et al. Sagittal deformities of the spine: factors influencing the outcomes and complications. Eur Spine J. 2015;24 Suppl 1:S3-15. 
20. Glassman SD, Berven S, Bridwell K et al. Correlation of Radiographic Parameters and Clinical Symptoms in Adult Scoliosis. Spine (Phila Pa 1976) 2005 Mar;30(6):682-8.

21. Lazennec JY, Ramaré $\mathrm{S}$, Arafati $\mathrm{N}$ et al. Sagittal alignment in lumbosacral fusion: relations between radiological parameters and pain. Eur Spine J. 2000;9(1):47-55.

22. Hallager DW, Hansen LV, Dragsted CR et al. A Comprehensive Analysis of the SRSSchwab Adult Spinal Deformity Classification and Confounding Variables. Spine (Phila Pa 1976). 2016 May;41(10):E589-97.

23. Schwab F, Patel A, Ungar B et al. Adult spinal deformity-postoperative standing imbalance: how much can you tolerate? An overview of key parameters in assessing alignment and planning corrective surgery. Spine (Phila Pa 1976). 2010;35(25):222431.

24. Chapman TM, Baldus CR, Lurie JD et al. Baseline Patient-Reported Outcomes Correlate Weakly With Radiographic Parameters. Spine (Phila Pa 1976). 2016 Nov;41(22):1701-8.

25. Takemoto M, Boissière L, Vital J-M et al. Are sagittal spinopelvic radiographic parameters significantly associated with quality of life of adult spinal deformity patients? Multivariate linear regression analyses for pre-operative and short-term postoperative health-related quality of life. Eur Spine J. 2016 Nov 18

26. Boissière L, Takemoto M, Bourghli A, Vital JM, Pellisé F, Alanay A, et al. Global tilt and lumbar lordosis index: two parameters correlating with health-related quality of life scores— but how do they truly impact disability? Spine J. 2017 Apr;17(4):480-488.

27. Carreon LY, Glassman SD, Shaffrey CI et al. Predictors of Health-Related Quality-ofLife After Complex Adult Spinal Deformity Surgery: A Scoli-RISK-1 Secondary Analysis. Spine Deform. 2017 Mar;5(2):139-44.

28. Lenke LG, Engsberg JR, Ross S a et al. Prospective dynamic functional evaluation of gait and spinal balance following spinal fusion in adolescent idiopathic scoliosis. Spine (Phila Pa 1976). 2001;26(14):E330-7.

29. Melamed E, Djaldetti R. Camptocormia in Parkinson’s disease. J Neurol. 2006 Dec;253 Suppl:VII14-16.

30. Mok NW, Brauer SG, Hodges PW. Hip strategy for balance control in quiet standing is reduced in people with low back pain. Spine (Phila Pa 1976). 2004 Mar;29(6):E107-12. 
31. Brumagne S, Janssens L, Janssens $\mathrm{E}$ et al. Altered postural control in anticipation of postural instability in persons with recurrent low back pain. Gait Posture. 2008 Nov;28(4):657-62.

32. Brumagne S, Janssens L, Knapen S et al. Persons with recurrent low back pain exhibit a rigid postural control strategy. Eur Spine J. 2008 Sep;17(9):1177-84.

33. Kallman DA, Plato CC, Tobin JD. The role of muscle loss in the age-related decline of grip strength: cross-sectional and longitudinal perspectives. J Gerontol. 1990 May;45(3):M82-8.

34. Dubousset J. Three-dimensional analysis of the scoliotic deformity, in Weinstein SL (ed): In: Weinstein S, editor. The Pediatric Spine: Principles and Practice. New York: Raven Press; 1994. p. 479-96.

35. Obeid I, Hauger O, Aunoble S et al. Global analysis of sagittal spinal alignment in major deformities: correlation between lack of lumbar lordosis and flexion of the knee. European Spine Journal. 2011;1-5.

36. Diebo BG, Ferrero E, Lafage R et al. Recruitment of Compensatory Mechanisms in Sagittal Spinal Malalignment Is Age and Regional Deformity Dependent. Spine (Phila Pa 1976) 2015;40(9):642-9.

37. Schwab F, Lafage V, Boyce R et al. Gravity Line Analysis in Adult Volunteers AgeRelated Correlation With Spinal Parameters, Pelvic Parameters , and Foot Position. Spine (Phila Pa 1976) 2006;31(25):E959-67.

38. Barrey C, Roussouly P, Perrin G et al. Sagittal balance disorders in severe degenerative spine. Can we identify the compensatory mechanisms? European Spine Journal. 2011;1-8.

39. Ferrero E, Liabaud B, Challier V et al. Role of pelvic translation and lower-extremity compensation to maintain gravity line position in spinal deformity. J Neurosurg Spine. 2015;1-11.

40. Liu S, Ferrero E, Liabaud B et al. Global sagittal alignment analysis including lower extremities: Role of pelvic translation and the lower extremities in compensation for spinal deformity. Spine Journal 2014. p. S138. 
41. Lafage R, Protopsaltis T, Diebo B et al. Identifying thoracic compensation and predicting reciprocal thoracic kyphosis and PJK. European Spine Journal. 2015. p. S765-6.

42. Tamura T, Otaka Y, Konno S et al. The Impaired Balance Systems Identified by the BESTest in Older Patients With Knee Osteoarthritis. PM R. 2016 Sep;8(9):869-75.

43. Norén a M, Bogren U, Bolin J et al. Balance assessment in patients with peripheral arthritis: applicability and reliability of some clinical assessments. Physiother Res Int. 2001;6(4):193-204.

44. Chan ACM, Pang MYC. Assessing Balance Function in Patients With Total Knee Arthroplasty. Phys Ther. 2015;95(10):1397-407.

45. Chou C-Y, Chien C-W, Hsueh I-P et al Developing a short form of the Berg Balance Scale for people with stroke. Phys Ther. 2006;86(2):195-204.

46. Schlenstedt C, Brombacher S, Hartwigsen G et al. Comparison of the Fullerton Advanced Balance Scale, Mini-BESTest, and Berg Balance Scale to Predict Falls in Parkinson Disease. Phys Ther. 2016 Apr; 96(4):494-501.

47. King LA, Priest KC, Salarian A et al. Comparing the Mini-BESTest with the Berg Balance Scale to evaluate balance disorders in Parkinson's disease. Parkinsons Dis. 2012; 2012:37541

48. Berg K, Wood-Dauphinee S, Williams JI. The Balance Scale: reliability assessment with elderly residents and patients with an acute stroke. Scand J Rehabil Med. 1995;27(1):27-36.

49. Downs S, Marquez J, Chiarelli P. Normative scores on the Berg Balance Scale decline after age 70 years in healthy community-dwelling people: A systematic review. $\mathrm{J}$ Physiother. 2014;60(2):85-9.

50. Duncan RP, Leddy AL, Cavanaugh JT et al. Balance differences in people with Parkinson disease with and without freezing of gait. Gait Posture. 2015;42(3):306-9. 
51. Leddy AL, Crowner BE, Earhart GM. Functional gait assessment and balance evaluation system test: reliability, validity, sensitivity, and specificity for identifying individuals with Parkinson disease who fall. Phys Ther. 2011;91(1):102-13.

52. Downs S, Marquez J, Chiarelli P. The Berg Balance Scale has high intra- and interrater reliability but absolute reliability varies across the scale: A systematic review. J Physiother. 2013;59(2):93-9.

53. Reuben DB, Siu a L. An objective measure of physical function of elderly outpatients. The Physical Performance Test. J Am Geriatr Soc. 1990;38(10):1105-12.

54. Guralnik JM, Simonsick EM, Ferrucci L et al. A short physical performance battery assessing lower extremity function: association with self-reported disability and prediction of mortality and nursing home admission. J Gerontol. 1994;49(2):M85-94.

55. Hernandez D, Rose DJ. Predicting which older adults will or will not fall using the Fullerton Advanced Balance scale. Arch Phys Med Rehabil. 2008 Dec;89(12):230915.

56. Rose DJ, Lucchese N, Wiersma LD. Development of a Multidimensional Balance Scale for Use With Functionally Independent Older Adults. Arch Phys Med Rehabil. 2006;87(11):1478-85.

57. Verheyden G, Nieuwboer A, Feys H et al. Discriminant ability of the Trunk Impairment Scale: A comparison between stroke patients and healthy individuals. Disabil Rehabil. 2005;27(17):1023-8.

58. Verheyden G, Nuyens G, Nieuwboer A et al. Reliability and validity of trunk assessment for people with multiple sclerosis. Phys Ther. 2006;86(1):66-76.

59. Verheyden G, Nieuwboer A, De Wit L et al. Trunk performance after stroke: an eye catching predictor of functional outcome. J Neurol Neurosurg Psychiatry. 2007;78(7):694-8.

60. Verheyden G, Willems AM, Ooms L et al. Validity of the Trunk Impairment Scale as a Measure of Trunk Performance in People With Parkinson's Disease. Arch Phys Med Rehabil. 2007;88(10):1304-8.

61. Heyrman L, Molenaers G, Desloovere K et al. A clinical tool to measure trunk control in children with cerebral palsy: The Trunk Control Measurement Scale. Res Dev Disabil. 2011 Nov;32(6):2624-35. 
62. Horak FB, Wrisley DM, Frank J. The Balance Evaluation Systems Test (BESTest) to differentiate balance deficits. Phys Ther. 2009 May;89(5):484-98.

63. Chinsongkram B, Chaikeeree N, Saengsirisuwan V et al. Reliability and validity of the Balance Evaluation Systems Test (BESTest) in people with subacute stroke. Phys Ther. 2014;94(11):1632-43.

64. O’Hoski S, Sibley KM, Brooks D et al. Construct validity of the BESTest, miniBESTest and briefBESTest in adults aged 50 years and older. Gait Posture. 2015 Sep;42(3):301-5.

65. Duncan RP, Leddy AL, Cavanaugh JT et al. Comparative utility of the BESTest, miniBESTest, and brief-BESTest for predicting falls in individuals with Parkinson disease: a cohort study. Phys Ther. 2013;93(4):542-50.

66. Padgett PK, Jacobs J V, Kasser SL. Is the BESTest at its best? A suggested brief version based on interrater reliability, validity, internal consistency, and theoretical construct. Phys Ther. 2012;92(9):1197-207.

67. Moke L, Severijns P, Doskorova T et al. Introducing dynamic balance assessment in Adult Spinal Deformity. Gait Posture. 2016 Nov 2;49:153.

68. Moke L, Severijns P, Doskorova T et al. Impaired balance relates to poor function in adults with spinal deformity. Gait Posture. 2016 Nov 2;49:154-5.

69. Mancini M, Horak FB. The relevance of clinical balance assessment tools to differentiate balance deficits. Eur J Phys Rehabil Med. 2010 Jun;46(2):239-48.

70. Anson E, Thompson E, Odle BL et al. Influences of Age, Obesity, and Adverse Drug Effects on Balance and Mobility Testing Scores in Ambulatory Older Adults. J Geriatr Phys Ther. 2017 Jan 10;1.

71. Shin BM, Han SJ, Jung JH et al. Effect of mild cognitive impairment on balance. J Neurol Sci. 2011;305(1-2):121-5.

72. Tangen GG, Engedal K, Bergland A et al. Relationships between balance and cognition in patients with subjective cognitive impairment, mild cognitive impairment, and Alzheimer disease. Phys Ther. 2014;94(8):1123-34. 
73. O’Hoski S, Winship B, Herridge L et al. Increasing the clinical utility of the BESTest, mini-BESTest, and brief-BESTest: normative values in Canadian adults who are healthy and aged 50 years or older. Phys Ther. 2014;94(3):334-42.

74. The number of subjects per variable required in linear regression analyses. Austin P., Steyerberg E. Journal of Clinical Epidemiology (2015) Volume 68, Issue 6;627-636.

75. Discovering statistics using IBM SPSS statistics, 4th edition, Andy Field, Sage Publications, 2016, paragraph 8.2.2 Sample size in regression, p.313-314.

76. Glassman SD, Coseo MP, Carreon LY. Sagittal balance is more than just alignment: why PJK remains an unresolved problem. Scoliosis Spinal Disord 2016 Jan 22;11:1

77. Wong-Yu ISK, Mak MKY. Multi-dimensional balance training programme improves balance and gait performance in people with Parkinson's disease: A pragmatic randomized controlled trial with 12-month follow-up. Parkinsonism Relat Disord. 2015 Jun;21(6):615-21. 


\section{Figure legend 1:}

Left side: Subject standing in SRS-free standing finger-on-clavicle position during force plate instrumented 2D stereoradiographic acquisition of full body images (Iso=Isocenter, GL= Gravity Line projection,

Mean GL= Mean Gravity Line Projection).

Rightside: Schematic presentation of all measured sagittal Spinopelvic Parameters (PI=Pelvic Incidence, PT=Pelvic Tilt, SS=Sacral Slope, LL= Lumbar Lordosis from T12 to S1, TK=Thoracic Kyphosis from T1 to T12, SVA=Sagittal Vertical Axis, T1 SPI= T1 Spinopelvic Inclination, TPA= T1 Pelvic Angle, GSA= Global Sagittal Axis
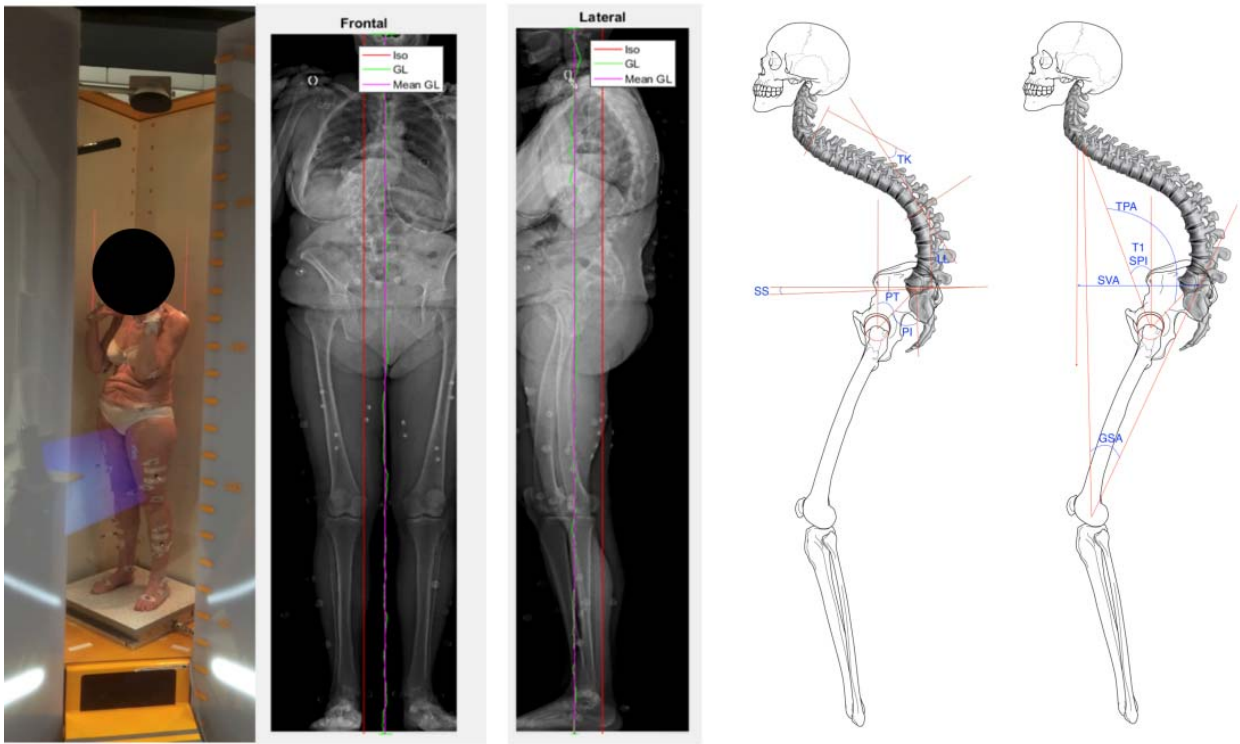
Figure legend 2: Subject performing dynamic tasks in BESTest (first row) and TCMS (second row).
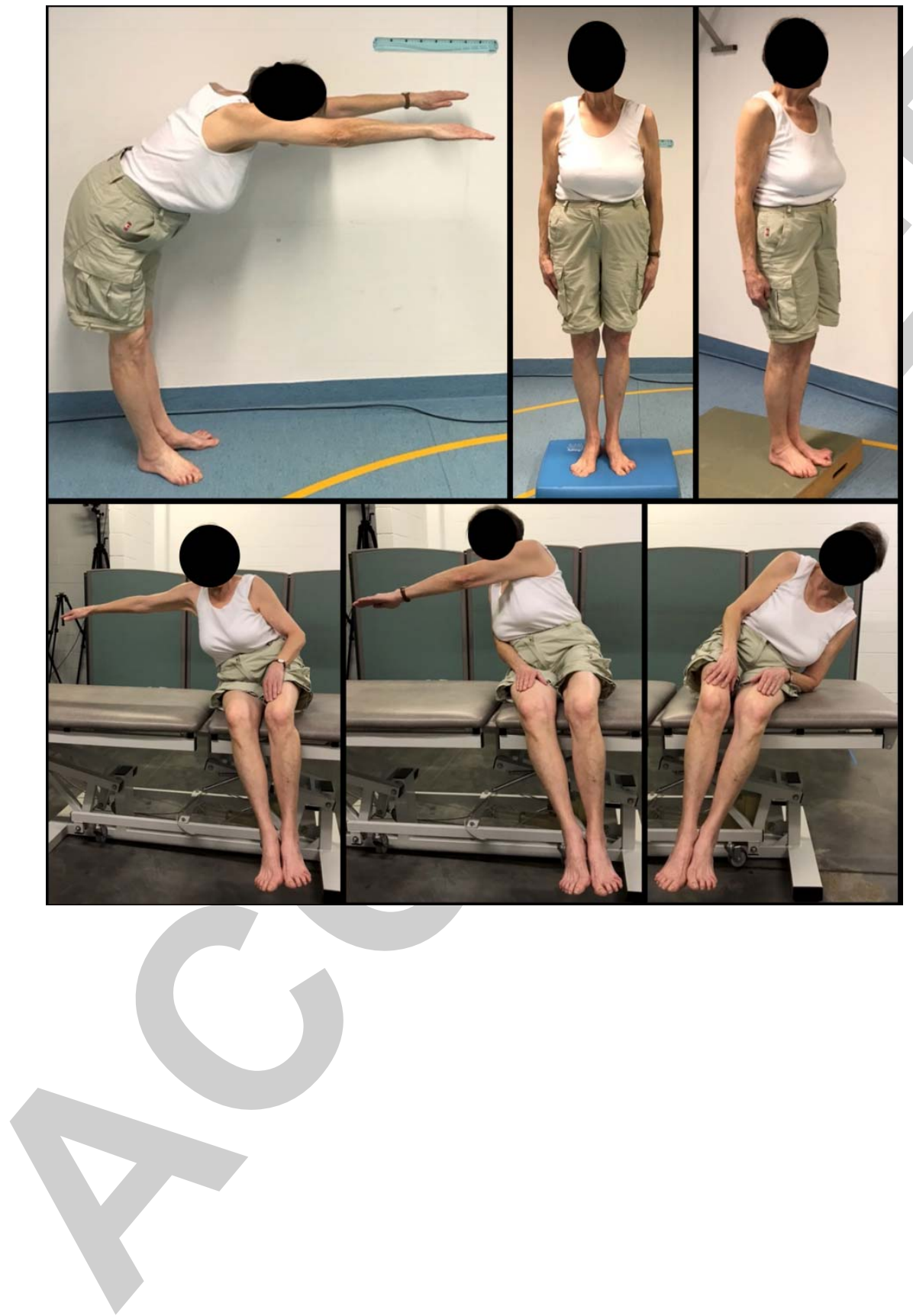

Copyright @ 2017 Wolters Kluwer Health, Inc. Unauthorized reproduction of this article is prohibited. 
Figure legend 3:Scatterplot of stepwise multivariate regression analysis with COMI as dependent variable showing the regression line in model 1 and 2 (left) with slope $=0,388$, the regression line in model 3 and 4 (middle) with slope $=-0,124$ and linear relationship between observed COMI versus predicted COMI in model 3 and 4 (right). COMI: Core Outcome Measures Index; CIRS: Cumulative Illness Rating scale; BESTest: Balance Evaluation Systems Test.
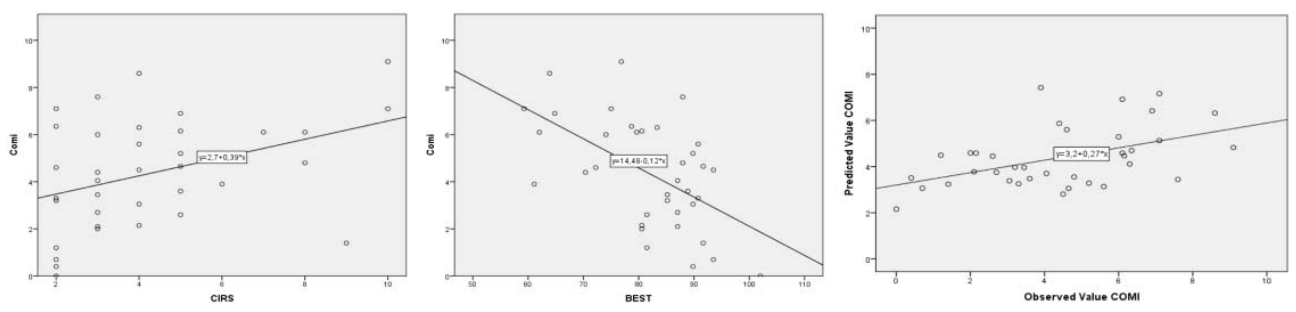


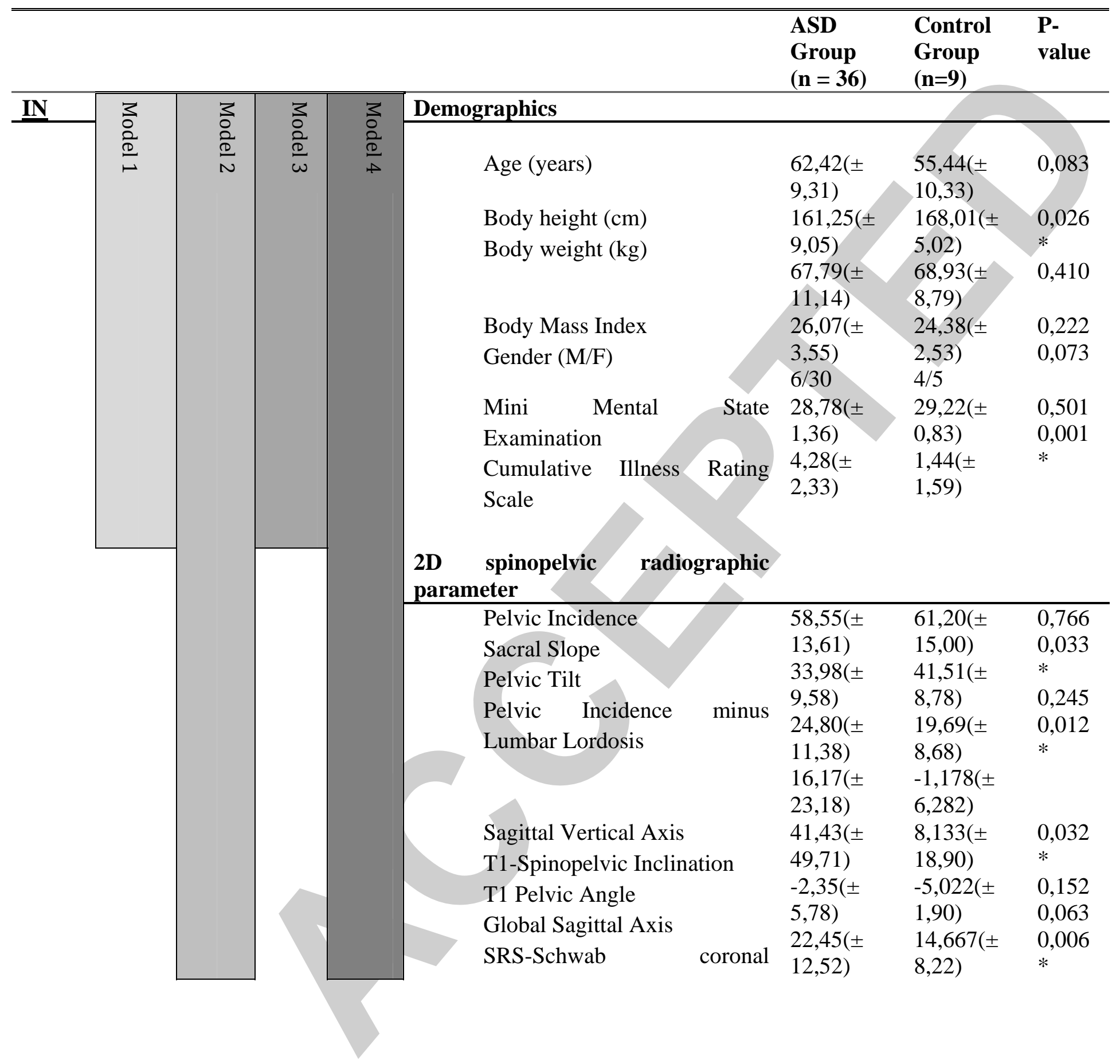

Copyright $\odot 2017$ Wolters Kluwer Health, Inc. Unauthorized reproduction of this article is prohibited. 


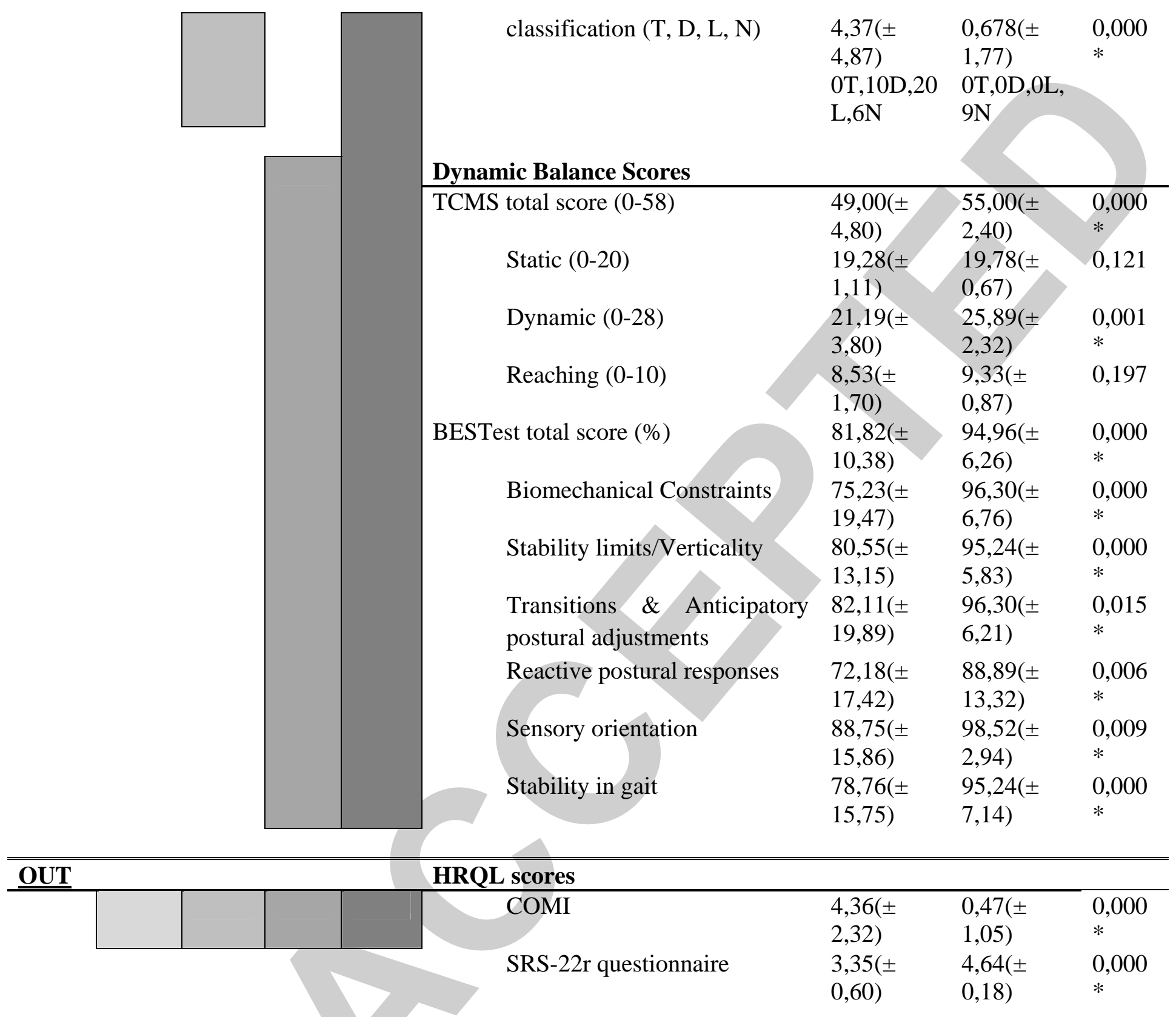


ODI

Table1: Comparison in demographics, HRQOL scores, 2D radiographic parameters and Dynamic Balance Scores for ASD group vs control group. Mean and standard deviations are reported. *Significance level $=\mathrm{p}<0,05$

Copyright @ 2017 Wolters Kluwer Health, Inc. Unauthorized reproduction of this article is prohibited. 
Univariate Analysis with COMI as dependent variable

\begin{tabular}{|c|c|c|c|}
\hline Variables & $\begin{array}{l}\text { Regression } \\
\text { coefficient }\end{array}$ & $\begin{array}{l}95,0 \% \\
\text { Confidence } \\
\text { Interval }\end{array}$ & P-Value \\
\hline \multicolumn{4}{|l|}{ Demographic variables } \\
\hline Age $^{2}$ & 2,702E-05 & $-0,001,0,001$ & 0,939 \\
\hline Gender & 0,712 & $-1,416,2,839$ & 0,501 \\
\hline $\mathbf{B M I}^{2}$ & 0,003 & $-0,001,0,007$ & 0,140 \\
\hline CIRS & 0,388 & $0,067,0,709$ & $0,019 *$ \\
\hline MMSE $^{2}$ & $-0,010$ & $-0,020,0,000$ & 0,054 \\
\hline \multicolumn{4}{|c|}{ 2D Spinopelvic radiographic parameters } \\
\hline $\mathbf{P I}^{2}$ & 0,000 & $0,000,0,001$ & 0,331 \\
\hline $\log (\mathrm{SS})$ & 0,844 & $-3,891,5,579$ & 0,720 \\
\hline $\mathbf{P T}^{2}$ & 0,001 & $-0,001,0,002$ & 0,320 \\
\hline PI-LL & 0,014 & $-0,020,0,049$ & 0,413 \\
\hline SVA & 0,003 & $-0,014,0,019$ & 0,750 \\
\hline T1 SPI ${ }^{2}$ & 0,003 & $-0,013,0,018$ & 0,709 \\
\hline sqrt(TPA) & 0,254 & $-0,400,0,908$ & 0,435 \\
\hline GSA & 0,043 & $-0,122,0,209$ & 0,599 \\
\hline $\begin{array}{l}\text { SRS-Schwab Coronal } \\
\text { Curve Classification }\end{array}$ & $-0,322$ & $-1,233,0,590$ & 0,478 \\
\hline \multicolumn{4}{|c|}{ Balance Tests (total score) } \\
\hline BESTest & $-0,124$ & $-0,189,-0,059$ & $0,000 *$ \\
\hline
\end{tabular}

Copyright @ 2017 Wolters Kluwer Health, Inc. Unauthorized reproduction of this article is prohibited. 
Multivariate Analysis with COMI as dependent variable

\begin{tabular}{|c|c|c|c|c|}
\hline $\begin{array}{l}\text { Variab } \\
\text { les }\end{array}$ & $\begin{array}{l}\text { Regression } \\
\text { coefficient }\end{array}$ & $\begin{array}{l}95,0 \% \\
\text { Confidence } \\
\text { Interval }\end{array}$ & \begin{tabular}{|l|l|}
$\mathbf{P}-$ & $\mathbf{R}^{2}-$ \\
Value & Value \\
\end{tabular} & $\begin{array}{l}\text { Adjusted R²- } \\
\text { Value }\end{array}$ \\
\hline
\end{tabular}

\section{Model 1 \& 2}

\begin{tabular}{|l|l|l|l|l|l|}
\hline $\begin{array}{l}\text { (Const } \\
\text { ant) }\end{array}$ & 2,700 & $1,143,4,257$ & 0,001 & & \\
\hline CIRS & 0,388 & $0,067,0,709$ & $\begin{array}{c}0,019 \\
*\end{array}$ & 0,151 & 0,126 \\
\hline
\end{tabular}

Copyright @ 2017 Wolters Kluwer Health, Inc. Unauthorized reproduction of this article is prohibited. 
Model 3 \& 4

\begin{tabular}{|l|c|c|c|c|c|}
\hline $\begin{array}{l}\text { (Const } \\
\text { ant) }\end{array}$ & 14,482 & $9,124,19,840$ & $\begin{array}{c}<0,00 \\
1^{*}\end{array}$ & & \\
\hline \begin{tabular}{l|l|l|l|} 
BESTe \\
st
\end{tabular} & $-0,124$ & $-0,189,-0,059$ & $\begin{array}{c}<0,00 \\
1^{*}\end{array}$ & 0,306 & 0,285 \\
\hline
\end{tabular}

st

Table2: Uni- and multivariate linear regression with COMI as dependent variable.

2: square transformation, log: logistic transformation, sqrt: square root transformation. Significant p-valuesare marked with *.

Copyright $\odot 2017$ Wolters Kluwer Health, Inc. Unauthorized reproduction of this article is prohibited. 